\title{
PHRASE-FINAL LENGTHENING AND STRESS-TIMED SHORTENING IN THE SPEECH OF NATIVE SPEAKERS AND JAPANESE LEARNERS OF ENGLISH
}

\author{
Motoko Ueyama \\ Department of Applied Linguistics and Phonetics Laboratory, Department of Linguistics, UCLA
}

(ueyama@humnet.ucla.edu)

\begin{abstract}
This study is intended to describe and analyze the durational patterns of native Japanese speakers learning English, with a focus on two major prosodic effects: phrase-final lengthening and stresstimed shortening. To investigate the relative contribution of these effects, a production experiment was conducted, adapting the methodological framework of Beckman and Edwards (1990). The effects of three degrees of boundary strength (the boundaries separating the members of a compound; two phonological phrases; and two intonational phrases) on the two phenomena were analyzed. Native English speakers, beginning Japanese learners of English, and advanced Japanese learners of English were compared.
\end{abstract}

\section{INTRODUCTION}

\subsection{Problem}

Difficulties in acquiring the temporal organization of English have been observed among native speakers of Japanese (MochizukiSudo \& Kiritani, 1991). Those difficulties appear to be caused by distinctive differences between Japanese and English in multiple aspects. In addition to the inventory size of segment and syllable types, the two languages greatly differ in prosodic realization, including temporal organization. The typological categorization of timing systems is rooted in the idea that temporal organization is based on some unit of timing, and Japanese is said to be moratimed, whereas English is stress-timed (Dauer, 1983). English timing is based on stress accent (i.e. on a local prosodic prominence that is lexically defined). One of the phonetic correlates of stress accent is duration, which is alternately stretched and reduced, interacting with the other two correlates, namely, fundamental frequency and amplitude. The unit of English timing is the stress foot, that is, a string containing a stress accent followed by zero or more unstressed syllables (Beckman and Edwards, 1990). On the other hand, the unit of Japanese timing is the mora (a syllabification unit): the duration of each mora is equal, abstracting away from the phrase-final lengthening effect that we will discuss later. The prosodic distinctions of Japanese is mainly conveyed by fundamental frequency (Beckman, 1986). These differences in the manipulation of the duration cue with respect to the other prosodic cues suggest that native speakers of Japanese will have considerable difficulty in learning English timing.

\subsection{Two Hypothesized Effects on English Timing Patterns}

Two crucial concepts concerning English temporal organization are phrase-final lengthening and stress-timed shortening. The phrase-final lengthening effect is usually defined as the lengthening of a rhyme (nucleus and coda) occurring before the boundary between prosodic constituents, roughly reflecting syntactic boundary strength (cf. Wightman et al., 1992 for English; Beckman \& Pierrehumbert, 1986; Kaiki et al, 1992 for Japanese).

The stressed-timed shortening effect is an indication of the tendency toward "isochronous spacing of prosodically strong syllables; a stressed syllable in a polysyllabic word or stress foot is compressed in order to make the overall duration of its word or stress foot closer to that of a contrasting monosyllable (Beckman \& Edwards 1990; 152)." Intervals between two stressed syllables are called "interstress intervals (ISIs)." The size of the stress foot is frequently used to denote the size of ISIs. The most prominent element in the stress foot is called the head of the foot. In the theory of isochrony, intervals between two heads are expected to be equalized. Consequently, the durations of stressed syllables will be shortened as the number of unstressed syllables between the two heads increases. This effect should characterize stresstimed languages.

\subsection{Purpose of the Study}

This study is intended to investigate the acquisition of phrase-final lengthening and stress-timed shortening by Japanese learners of English in comparison with native speakers of English. As Beckman and Edwards (1990) point out, in the experimental design, it is crucial to prevent the two effects from being confounded with each other. The production experiment of Mochizuki-Sudo and Kiritani (1991) is subject to this criticism. For the purpose of this study, the two effects will be strictly distinguished in experimental design. The durational patterns of native Japanese speakers learning English will be described and analyzed with respect to the transfer of the Japanese timing system to the timing system of their English speech .

\section{EXPERIMENT}

\subsection{Subjects}

The set of speakers included one control group and two experimental groups; each group consisted of four speakers (two males and two females). The control group (NS group) consisted of native speakers of American English. The first experimental group (the AJ group) consisted of advanced Japanese learners of English, and the second experimental group (the BJ group) consisted of beginning Japanese learners of English. In order to equalize proficiency across speakers in the same experimental 
group, the Japanese participants were selected using several criteria: years of residence in the U.S. (3 years for the AJ; none for the $\mathrm{BJ}$ ), age range (25-31 for the $\mathrm{AJ} ; 22-25$ for the $\mathrm{BJ}$ ), language background, and previous learning experience.

\subsection{Procedure}

The subjects' assigned task was to read a list of randomized sentences. Each sentence was read twelve times, and the first and last two repetitions were omitted in the subsequent measurement of phonetic durations. The performances were recorded with highquality equipment in the soundproof room of the UCLA Phonetics Laboratory for the AJ group and in the recording booth of the Doosisya Women's College in Japan for the BJ group.

The recorded data were converted from analog to digital at a 10 $\mathrm{kHz}$ sampling rate, and analyzed using Kay Elemetrics' Computerized Speech Laboratory (CSL) hardware and software. Since final lengthening mainly affects phrase-final syllables (Wightman, et al., 1992), and the relevant syllables had no consonantal coda, I measured the duration of stressed and unstressed vowels in both pre- and post-boundary positions for each prosodic level. All the measurements were carried on the waveform analysis, and wide-band spectrographs were additionally inspected in the cases of difficult segmentation.

\subsection{Materials}

The data sets for the production experiment are shown in (1-A, B, C). The two stressed vowels determining the size of ISI are indicated by acute accent marks; the analyzed stressed and unstressed vowels are denoted by bold-face and underline, respectively. The three sentence sets $(1-\mathrm{A}, \mathrm{B}, \mathrm{C})$ test the three degrees of boundary strength predicted by the theory of prosodic hierarchy (see Hayes 1989 for a review): boundary strength is weakest for the set (1-A) and strongest for the set (1-C).

(1)
A. Boundary separates members of a compound
a. I met Lée ] Mótt last week.
b. I met Lée] DẹMótt last week.
c. I met Léda] Mótt last week.
d. I met Léda] DeMótt last week.

B. Boundary follows the end of a phonological phrase.

a. My pá] zíps along in traffic.

b. My pá] posítions himself well in traffic.

c. My pápa] zíps along in traffic.

d. My pápa] posítions himself well in traffic.

C. Boundary follows the end of an intonational phrase.

a. My pá], góat lover though he is, would never buy one.

b. My pá], pagóda lover though he is, would never buy one.

c. My pápa], góat lover though he is, would never buy one.

d. My pápa], pagóda lover though he is, would never buy one.

For each set, the pair $(\mathrm{a}, \mathrm{b})$ strictly tests for two different degrees of stress-timed shortening (ISI $=0 \mathrm{vs}$. ISI $=1$ ), holding phrasefinal lengthening constant (i.e. putting a boundary in the same position relevant with respect to the pre-boundary noun). In the same way, the pair $(\mathrm{c}, \mathrm{d})$ examines the difference between ISI $=1$ and ISI $=2$. The pair $(b, c)$ strictly tests for phrase-final lengthening, holding the size of interstress interval constant (ISI = 1). The structure of the experimental design is summarized in Table 1. These pairs were compared in two-tailed t-tests.

\begin{tabular}{|c|c|c|c|}
\hline test for & $\begin{array}{l}\text { informative } \\
\text { pairs }\end{array}$ & $\begin{array}{l}\text { expected } \\
\text { final } \\
\text { lengthening }\end{array}$ & ISI size \\
\hline $\begin{array}{l}\text { phrase-final } \\
\text { lengthening }\end{array}$ & $\begin{array}{l}\text { (b) vs. (c) } \\
\text { e.g. pá] posítions } \\
\text { vs. pápa] zíps }\end{array}$ & $\begin{array}{l}\text { yes for stressed } \\
\mathrm{V} \text { in (b) and } \\
\text { unstressed V in } \\
\text { (c); no for } \\
\text { unstressed V in } \\
\text { (b) and stressed } \\
\text { V in (c) }\end{array}$ & $\begin{array}{l}\text { constant } \\
(\text { ISI }=1)\end{array}$ \\
\hline $\begin{array}{l}\text { stress-timed } \\
\text { shortening }\end{array}$ & $\begin{array}{l}\text { (a) vs. (b) } \\
\text { e.g. pá] zíps } \\
\text { vs. pá] posítions } \\
\text { (c) vs. (d) } \\
\text { e.g. pápa] zíps } \\
\text { vs. pápa]]posítions }\end{array}$ & $\begin{array}{l}\text { constant (yes } \\
\text { for stressed } \mathrm{V} \text { ) } \\
\text { constant (no } \\
\text { for stressed } \mathrm{V})\end{array}$ & $\begin{array}{l}\text { ISI }=0 \text { vs. } 1 \\
\text { ISI }=1 \text { vs. } 2\end{array}$ \\
\hline
\end{tabular}

Table 1: Sentence pairs tested for phrase-final lengthening and stress-timed shortening.

\section{RESULTS \& DISCUSSION}

Vowel durations in each condition were statistically analyzed by using ANOVA and two-tailed t-tests. The effects of the two prosodic phenomena under consideration were examined separately.

\subsection{Similar Patterns in the Three Groups}

The results of the NS group reliably showed a major phrase-final lengthening effect before both phonological-phrase and intonationphrase boundaries, but word-final lengthening effects varied across and within speakers. The data from a representative speaker, NS1, are shown in Figure 1, and the statistical results are summarized in Table 2. IF, PF, and WF are abbreviated for Intonational-Phrase Final, Phonological-Phrase Final, and Word Final boundaries.

\begin{tabular}{|l|l|c|c|c|}
\hline Stressed V & & WF & PF & IF \\
\hline final lengthening & (b) vs. (c) & .059 & $\mathrm{p}<.001$ & $\mathrm{p}<.001$ \\
\hline stress-timed & (a) vs. (b) & .697 & .172 & .022 \\
shortening & (c) vs. (d) & .118 & .230 & .435 \\
\hline
\end{tabular}

\begin{tabular}{|l|l|c|c|c|}
\hline Unstressed V & & WF & PF & IF \\
\hline final lengthening & (b) vs. (c) & .059 & $\mathrm{p}<.001$ & $\mathrm{p}<.001$ \\
\hline
\end{tabular}

Table 2. Results of two-tailed t-tests in p-values for the data of NS1. The shaded cells indicate $\mathrm{p}$-values above the critical value $(\alpha=0.05)$. 
Similar patterns were observed in the data of all the four AJ speakers and the four BJ speakers.

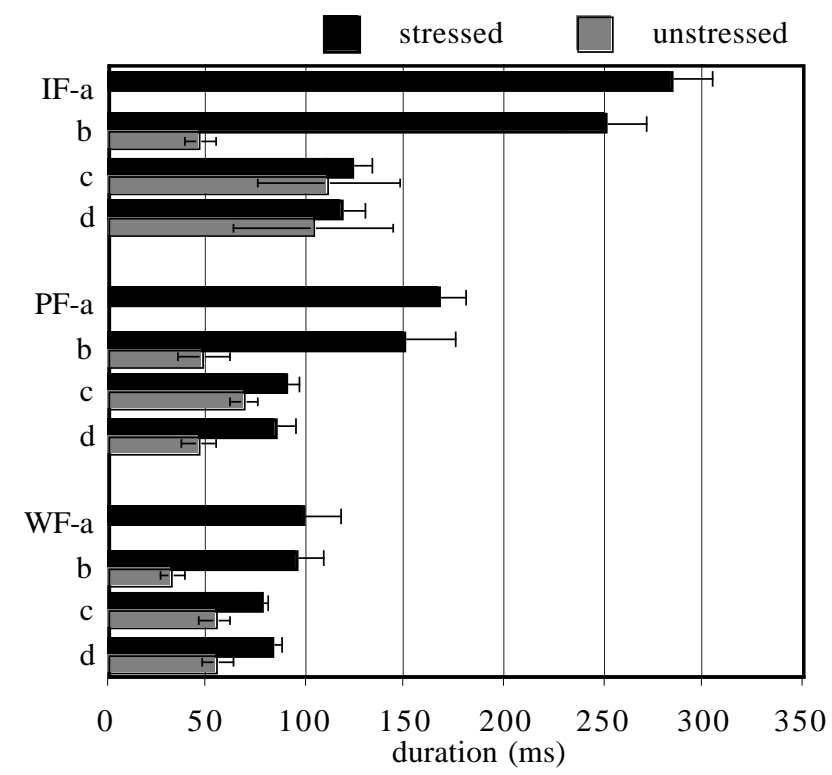

Figure 1: Mean durations of stressed and unstressed vowels of NS1.

\subsection{Major Effects in Japanese Learners' Speech}

The production data of the three groups showed considerable phrase-final lengthening and no stress-timed shortening, and these patterns were statistically confirmed. What factor differentiates the durational patterns of the three groups, if any? Further statistical analyses show the following two major peculiarities in the speech of Japanese learners.

First, less advanced Japanese learners make less durational contrast between lexically stressed and unstressed vowels than native English speakers. I assume this to be due to the negative transfer of Japanese "durational immalleability" (i.e. the fact that there is no durational contrast between pitch-accented and unaccented moras). The strong correlation between the speaker groups and the degree of durational contrast between stressed and unstressed vowels is shown by plotting the mean ratio of stressed $\mathrm{V}$ to an unstressed $\mathrm{V}$ adjacent to a prosodic boundary (i.e. not in a final lengthening context) for the set (1-C). The results are shown in Figure 2.

Second, less advanced learners made less hierarchical differentiation of boundary strength. Additional statistics was conducted in order to see how the different groups differentiate the three degrees of boundary strength by duration. For each sentence set, the means of stressed vowels in the environment (b) were compared with the means of stressed vowels in the environment (c): e.g. (b) pá J, pagóda vs. (c) pápa], góat for the (1-C) set. This comparison allows us to measure the differentiation of boundary strength and the degree of final lengthening by holding the ISI size constant (ISI =1). The three sentence sets designed for this study reflect three degrees of boundary strength (WF $<\mathrm{PF}<\mathrm{IF}$ ). This order is expected to be systematically marked by the degree of final lengthening. The mean ratio of stressed vowels in the environment (b) to unstressed vowels in the environment (c) is compared across the three groups in Figure 3. The NS group clearly distinguishes the three degrees of boundary strength in the hypothesized order WF $<\mathrm{PP}<\mathrm{IF}$. Overall, the native speakers have more final lengthening for stressed syllables before stronger boundaries. This pattern is followed by the AJ group except AJ1. The patterns of the BJ group show more variations across the speakers. BJ1 seems to show almost native-like differentiation of the three levels, whereas the other three speakers do not. BJ2 makes no differentiation, and $\mathrm{BJ} 3$ and $\mathrm{BJ} 4$ make minor differentiation.

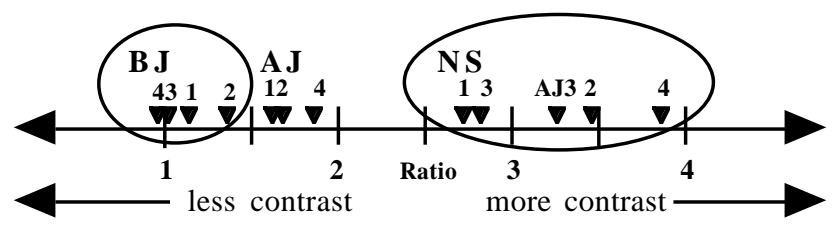

Figure 2: Ratio of mean durations. Stressed V in (c) pápa], góat were divided by unstressed $\mathrm{V}$ in (b) pá], pa góda for the (1-C) set.

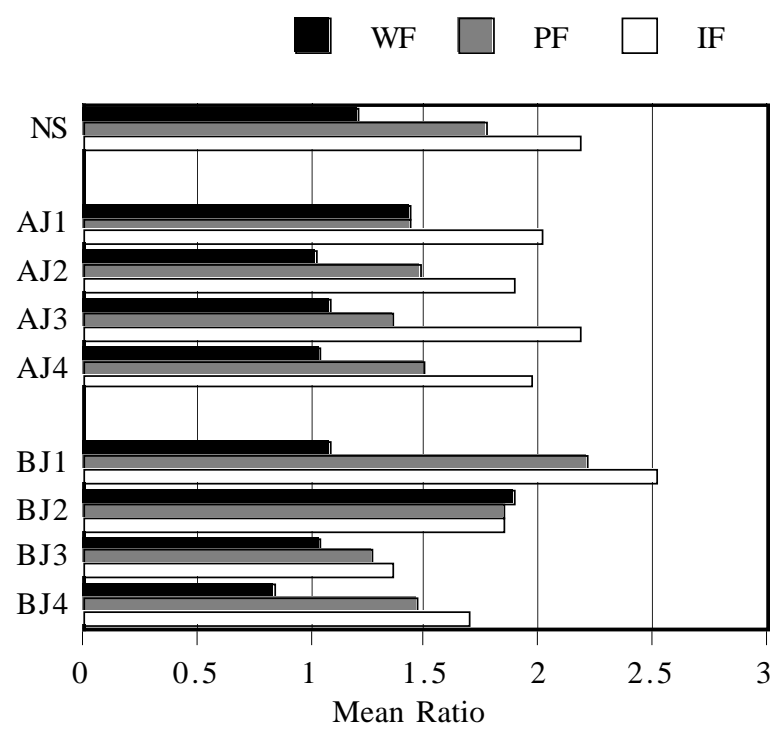

Figure 3: Mean ratio of stressed vowels in (b) to stressed vowels in (c).

However, the similar pattern in ratio does not imply a similar pattern in actual magnitude of lengthening. Figure $\mathbf{4}$ shows raw values of vowel durations in the three prosodic positions for the three speaker groups. In the environment (b), all native English speakers significantly increase the actual duration proportionally (WF < PF < IF). The same hierarchical differentiation is made in the environment (c) as well. This pattern is shown by only two Japanese speakers (AJ2 and AJ4). The other six Japanese speakers tend to over-apply final lengthening before smaller 
boundaries. This results in a greater magnitude of lengthening before smaller boundaries and less hierarchical differentiation of boundary strength .

\section{CONCLUSION}

The detailed comparison of the three speaker groups demonstrates that Japanese timing patterns are influential in two ways. First, there is a primary negative transfer of mora immaleability, which is a Japanese specific feature. This constitutes a major difficulty in acquiring durational contrasts between lexically stressed and unstressed syllables in English. Second, there is a possible positive transfer of Japanese prepausal lengthening in larger boundaries, which may be a language-universal phenomenon.

To further explore the general mechanism of timing development in second language phonetics, we need cross-linguistic investigation of other cases, such as the English speech of second language learners whose first language is syllable-based (e.g. French) and the Japanese speech of second language learners whose first language is stress-timed (e.g. English)

\section{REFERENCES}

1. Beckman, M. E. Stress and Non-stress Accent. Dordrecht: Foris Publication, 1986.

2. Beckman, M. E., \& Edwards, J. "Lengthening and shortening and the nature of prosodic constituency", Laboratory Phonology I, by J. Kingston and M. E. Beckman (eds.), Cambridge University Press, Cambridge, 152-178, 1990.

3. Beckman, M. E., \& Pierrehumbert, J. "Intonational structure in Japanese and English", Phonology Yearbook, 3, 255-309, 1986.

4. Dauer, R. "Stress-Timed and Syllable-timing reanalyzed", $J$ of Phonetics 11, 51-62, 1983.

5. Hayes, B. P. "The Prosodic Hierarchy in Meter", Phonetics and Phonology, Volume 1: Rhythm and Meter, by $\mathrm{P}$. Kiparsky \& G. Youmans, Academic Press, San Diego, 201 260, 1989.

6. Kaiki, N. et al. "Linguistic properties in the Control of Segmental Duration for Speech Synthesis", Talking Machines: Theories, Models, and Designs by G. Bailly, et al. (eds.), Elsvier Science Publishers B. V., 1992.

7. Mochizuki-Sudo, M., \& Kiritani, S. "Production and Perception of Stress-related Durational Patterns in Japanese Learners of English", Journal of Phonetics, 19 (2), 231-248, 1991.

8. Wightman, C. W., et al. "Segmental Durations in the Vicinity of Prosodic Phrase Boundaries", JASA 91(3), 1707-1717, 1992.

\section{A. Word Final}

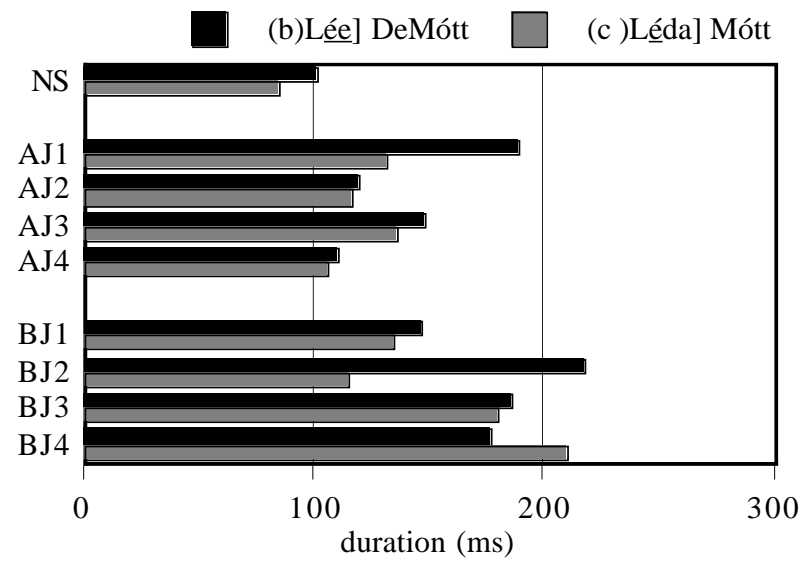

B. Phonological-Phrase Final

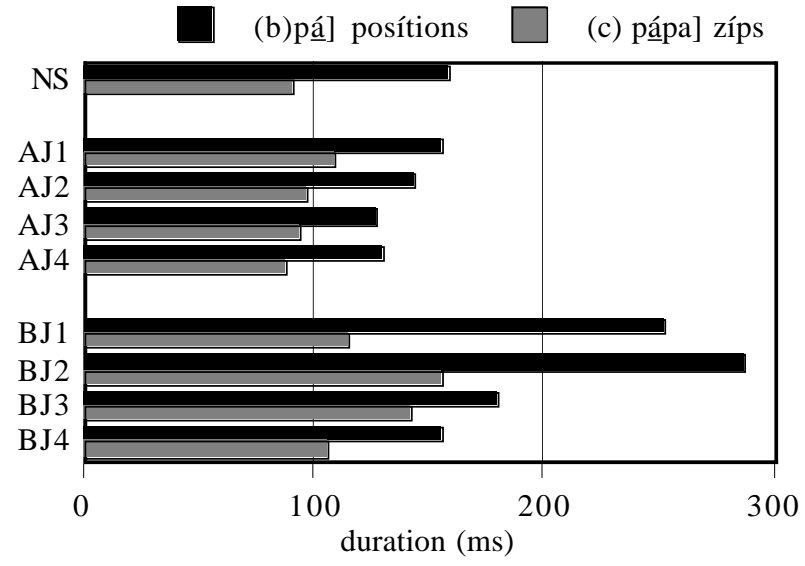

\section{Intonational-Phrase Final}

(b) pá], pagóda $\square$ (c) pápa], góat

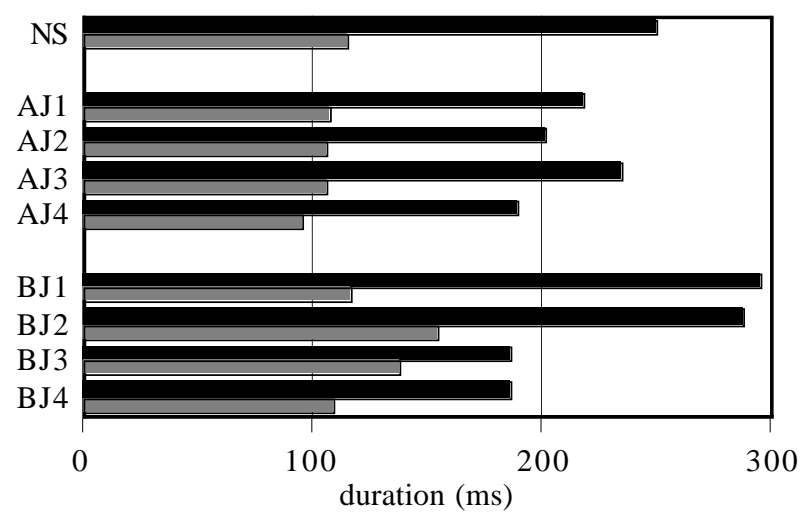

Figure 4: Mean durations of pre-boundary stressed vowels in the environments (b) and (c). 